\title{
Guía para la presentación de trabajos en la revista Pensamiento Actual
}

Objetivo. El objetivo de la Revista Educación de la Universidad de Costa Rica es difundir la investigación científica y promover la reflexión académica en diversos campos del quehacer universitario.

Periodicidad. Semestral. El primer número comprende desde enero hasta junio; el segundo, desde julio hasta diciembre.

Idiomas. Recibe artículos en español e inglés, portugués o francés.

Gratuidad. No cobra por ingreso o procesamiento de artículos.

Identificación. ISSN: 1409-0112 / e-ISSN: 2215-3586 Universidad de Costa Rica Revista Pensamiento Actual

Protección. Todos los artículos publicados, están protegidos con una licencia Creative Commons 3.0(Reconocimiento-NoComercialSinObraDerivada) de Costa Rica. Esta licencia se puede consultar en: http://creativecommons.org/ licenses/by-nc-nd/3.0/es/

Política de autoarchivo: La revista permite el autoarchivo de los artículos en su versión arbitrada, editada y aprobada por el Consejo Editorial de la Revista Pensamiento Actual para que estén disponibles en Acceso Abierto a través de Internet. Más información en el siguiente link: http://revistas. ucr.ac.cr/index.php/pensamientoactual

Descriptores temáticos: Brinda cobertura a una amplia variedad temática: todos aquellos que sean de orden académico, filosófico, científico, didáctico, cultural, social o artistico.

Política de acceso abierto. Esta es una revista de acceso abierto, lo cual implica que todo el contenido puede ser consultado libremente y sin costo alguno para el usuario. Los lectores pueden leer, descargar, copiar, distribuir, imprimir y buscar los artículos en esta revista sin solicitar permiso previamente del editor o al autor, siempre que su uso se corresponda con fines educativos, completamente ajenos al plano lucrativo.

Tipo de artículos. La Revista publica artículos inéditos de los siguientes tipos: artículo científico (texto con evidencia empírica y metodología bien delimitada) Máximo 25 páginas, estos son derivados de una investigación, experiencia de acción social o de docencia. Refiere los alcances logrados y sus posibles aplicaciones científicas. Debe plantear los objetivos, el método utilizado y los resultados. Debe expresar sus propios propósitos y mostrar independencia con respecto a la investigación que lo sustenta.

El ensayo bibliográfico. Máximo 25 páginas. Consiste en una síntesis comentada de informes de investigación, artículos de investigación, libros, entre otros, de un determinado ámbito de estudio relacionado con alguno de los temas que la Revista acepta.

El ensayo científico. Máximo 25 páginas. Es el tipo de texto que defiende una tesis o contrapone dos tesis o más acerca del objeto de estudio específico que trata. Es un discurso reflexivo en el que se enfatiza en el análisis de los estudios vigentes y las ideas planteadas hasta ese momento en un tema específico, con el objetivo discutir acerca de sus alcances y relevancia.

La semblanza. Máximo 25 páginas. Es un bosquejo biográfico que destaca los eventos más sobresalientes relacionados con algún ámbito de investigación que determinaron el carácter, los 
estudios y la relevancia histórica de un personaje o institución. Se reconocen sus logros y alcances en su campo de estudio y cómo sus acciones modificaron el curso de la historia del país o del saber específico. Se reconoce la marca que la persona dejó.

Reseñas. Máximo 25 páginas. Se trata de textos que resumen experiencias en relación con proyectos, iniciativas, políticas culturales, educativas, artísticas o en salud y textos literarios. Se presentan con el rigor de un ensayo pero permiten la apreciación subjetiva de quien escribe.

Otras colaboraciones: textos literarios breves o documentos de arte visual con su respectivo análisis preliminar.

Cesión de derechos autorales. Para la aceptación del artículo, los autores ceden a la Revista Pensamiento Actual de forma gratuita, exclusiva y por plazo indefinido. Los autores aceptan que los textos sean ajustados por el equipo de edición, según la "Guía para la presentación de artículos de la Revista Pensamiento Actual", establecidas y publicadas en el sitio web oficial de la Revista http:// revistas.ucr.ac.cr/index.php/pensamientoactual. En esta guía se refieren procedimientos, estilo, formato, corrección, edición, traducción, publicación, duración del proceso editorial y otros requerimientos solicitados en la normativa. Esta cesión debe realizarse por escrito.

Sistema de arbitraje. La Revista Pensamiento Actual solo recibirá artículos que cumplan con las temáticas y los formatos descritos. Los artículos que no se ajusten a estas especificaciones serán devueltos para su correspondiente ajuste por parte del autor.

Todos los artículos aceptados serán evaluados por dos lectores externos a la Revista en la modalidad de "doble ciego"; es decir, los autores desconocerán quién los evaluará y los lectores desconocerán a quién pertenece la autoría del texto que valoran.

Resultados de evaluación: Ser publicado, ser publicado si atiende recomendaciones, quedar pendiente su publicación (faltan datos) y no publicarse.

En caso de no haber consenso entre las personas evaluadoras, el escrito se someterá a una tercera lectura, para que su criterio permita decidir si se publica o no se publica.

Las observaciones serán enviadas a los autores y cuando las observaciones hayan sido contempladas, se recibirá la versión final del autor.

Dictamen definitivo. Será el Comité editorial, en reunión, quien emitirá el dictamen definitivo, sobre los textos ya corregidos en versión final del autor.

Ajustes finales. Una vez aprobados los artículos para el volumen y número correspondiente se procederá a la corrección filológica que, en Pensamiento Actual, sigue las normas de escritura discutidas por la Real Academia Española (en el caso de los textos en español), por lo que no se emplea el mal llamado lenguaje inclusivo. Luego se realizará la diagramación y su publicación.

La Revista Pensamiento Actual publicará resultados de investigaciones, ensayos y notas técnicas en los diversos campos del quehacer universitario. Se aceptan trabajos originales e inéditos, relacionados con diversas disciplinas, producto de la actividad académica con el objetivo de difundir conocimientos y experiencias desarrolladas en la Sede de Occidente o fuera de ella.

La originalidad de cada propuesta dependerá de: que presente un tema novedoso o un enfoque innovador en temas que ya hayan sido tratados; que aplique una metodología nueva o diferente para tratar un tema o que sea una revisión de un tema que muestre una nueva relación entre contenidos o autores con aportes sustanciales.

El escrito no sobrepasará las 25 páginas (papel 8,5 x 11, letra Arial tamaño 12 y a doble espacio). Los márgenes serán superior: $3 \mathrm{~cm}$, inferior: $4 \mathrm{~cm}$, izquierdo: $4 \mathrm{~cm}$, derecho: $3 \mathrm{~cm}$.

El título de cada trabajo debe ser sintético, no abarcar más de 12 palabras. El título debe ir -cuando menos- en inglés y en español. Debajo de este se hará constar el nombre del autor o de los autores e indicar el grado académico, su especialidad y la dirección convencional o electrónica donde pueda ser localizado; además debe señalarse la institución 
con la que se relaciona profesionalmente el autor o cada uno de los autores.

Los artículos científicos deberán ir precedidos de un resumen en español y otro en inglés no mayor de 300 palabras, en el que se defina el contenido del trabajo de manera rigurosa, con indicación expresa sobre los objetivos y los resultados. Igualmente, deben anotarse un mínimo de 5 palabras clave, tanto después del resumen en español, como del resumen en inglés, en este caso las palabras irán en inglés, después de la leyenda "Keywords".

El texto deberá subdividirse en las partes necesarias para su clara exposición y correcta comprensión, por ejemplo: introducción, materiales y métodos, conclusión, bibliografía.

Si el artículo contiene cuadros, mapas, gráficos e ilustraciones deben venir claramente copiados (máxima calidad) en la versión digital. La cronología y la escala deben aparecer en la figura (nunca en el pie). Se evitarán los cuadros muy extensos o muy pequeños; igualmente, deben indicarse los créditos de toda imagen, cuadro, diagrama, figura, fotografía o mapa.

Cada artículo presentado debe incluir la bibliografía utilizada. Esta se asignará al final, en orden alfabético y sin hacer distinciones entre los tipos de documentos. Para su elaboración se utilizarán las normas de la American Psychological Association (APA), el Sistema Harvard, o el que resulte más adecuado para la disciplina del texto.

Toda bibliografía debe incluir los siguientes datos en la secuencia que corresponda al estilo de citación.

Para un libro: Autor. (Año). Título. Edición. Ciudad: Editorial, páginas.

Para artículo: Autor. Año. Título del artículo. Título de la revista, volumen (número): páginas.

Para tesis: Autor. (Año). Título. (Tesis, grado). Ciudad: Universidad.

Para eventos: Autor. (Año). Título de la ponencia. Título del evento. (número: lugar: fecha). Lugar: Editorial, páginas.

Para fuentes de Internet: Autor. (Año). Título. Lugar: Publicador. Disponible en: URL (fechas de acceso).
Las notas explicativas deberán colocarse con una llamada numérica y remitirse al pie de página.

Este consejo se reserva el derecho de hacer cambios en el original con el fin de mantener la homogeneidad y la calidad de la publicación, sin embargo, el estilo. Una vez aceptado el trabajo para su publicación, no puede ser publicado en otro medio de difusión sin la autorización previa del Editor.

\section{Sistema de arbitraje}

Los artículos se reciben en la dirección electrónica pensamientoactual.so@ucr.ac.cr y en pensamientoactual.so@gmail.com; se le agradece a los autores que empleen ambas direcciones para evitar extravíos de material. Igualmente, los autores pueden entregar una versión digital y una en papel en la Coordinación de Investigación de la Sede de Occidente. No se aceptan contribuciones que no cumplan con las normas establecidas por el Consejo Editorial de la Revista.

Una vez recibido el artículo, el autor recibirá un correo electrónico en el que se corroborará su recepción, en este se indicará el título del artículo, el autor y la fecha, para el orden de los registros. Todos los artículos recibidos serán sometidos a un sistema de evaluación con evaluadores anónimos, externos a la Revista y de ser posible, relacionados con centros de invesigación o de docencia fuera de Costa Rica, siempre se tratará de especialistas en el área del conocimiento correspondiente al tema tratado en el artículo por evaluar.

Los evaluadores tendrán un mes calendario para dictaminar el artículo y, si es aceptado por el Consejo Editorial, se le comunicará por escrito al autor la decisión, quien tendrá quince días hábiles para efectuar las modificaciones correspondientes y remitir de nuevo su trabajo al Director de la Revista. Junto con la versión final del artículo, deberá adjuntar una declaración jurada en la que se haga constar la originalidad del artículo, así como que no ha sido publicado ni se publicará en otro medio, ya sea escrito o electrónico. 


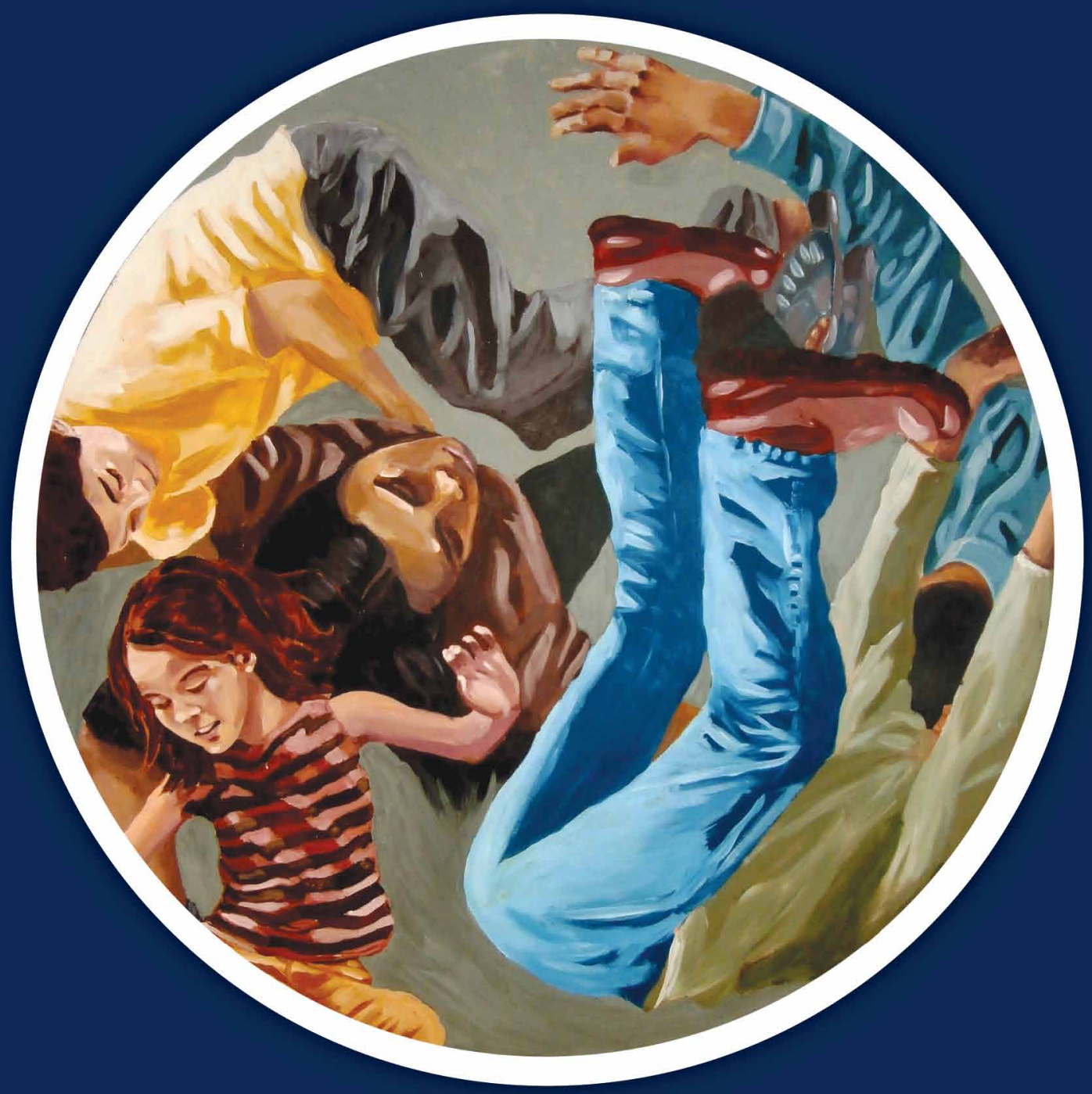

La Revista Pensamiento Actual es una publicación multidisciplinaria de la Sede de Occidente de la Universidad de Costa Rica que se publica semestralmente. Está abierta al debate y admite artículos de carácter científico y académico, originales, cuyas ideas y conceptos no necesariamente coinciden con los de la Sede de Occidente. La responsabilidad de los trabajos publicados es exclusiva de sus autores y son evaluados, según su contenido, tanto por la Comisión Editorial como por especialistas externos pertenecientes a otras unidades académicas de la Universidad de Costa Rica y de otras universidades, centros o institutos de investigación, tanto nacionales como extranjeros. 